\title{
The Registry and Follow-Up of Complex Pediatric Therapies Program of Western Canada: A Mechanism for Service, Audit, and Research after Life-Saving Therapies for Young Children
}

\author{
Charlene M. T. Robertson, ${ }^{1,2,3}$ Reg S. Sauve, ${ }^{4,5}$ Ari R. Joffe, ${ }^{1,6}$ Gwen Y. Alton, ${ }^{2,6}$ \\ Diane M. Moddemann, ${ }^{7,8}$ Patricia M. Blakley, ${ }^{90}$ Anne R. Synnes, ${ }^{11}, 12$ Irina A. Dinu, ${ }^{13}$ \\ Joyce R. Harder, ${ }^{4,14}$ Reeni Soni, ${ }^{7,} 15$ Jaya P. Bodani,, ${ }^{, 16}$ Ashok P. Kakadekar,, 17 \\ John D. Dyck, ${ }^{1,} 18$ Derek G. Human, ${ }^{19}$ David B. Ross, ${ }^{20}$ and Ivan M. Rebeyka ${ }^{1,20}$ \\ ${ }^{1}$ Department of Pediatrics, University of Alberta, Edmonton, AB, Canada T6G 2R3 \\ ${ }^{2}$ Complex Pediatric Therapies Follow-Up Program, Glenrose Rehabilitation Hospital, Room 242, GlenEast, $10230-111$ Avenue, \\ Edmonton, AB, Canada T5G 0B7 \\ ${ }^{3}$ Pediatric Rehabilitation Outcomes Evaluation and Research Unit, Glenrose Rehabilitation Hospital, Room 242, GlenEast, \\ 10230-111 Avenue, Edmonton, AB, Canada T5G 0B7 \\ ${ }^{4}$ Department of Pediatrics, University of Calgary, Calgary, AB, Canada T2N 1N4 \\ ${ }^{5}$ Perinatal Follow-Up Clinic, Alberta Children's Hospital, Calgary, AB, Canada T3B 6AB \\ ${ }^{6}$ Pediatric Intensive Care Unit, Stollery Children's Hospital, Edmonton, AB, Canada T6G 2B7 \\ ${ }^{7}$ Department of Pediatrics and Child Health, University of Manitoba, Winnipeg, MB, Canada R3E 0Z2 \\ ${ }^{8}$ Neonatal Follow-Up Clinic, Children's Hospital of Winnipeg, Winnipeg, MB, Canada R3A $1 S 1$ \\ ${ }^{9}$ Department of Pediatrics, University of Saskatchewan, Saskatoon, SK, Canada S7N OW8 \\ ${ }^{10}$ Alvin Buckwold Child Development Program, Kinsmen Children's Center, Saskatoon, SK, Canada S7N $2 Z 1$ \\ ${ }^{11}$ Department of Pediatrics, University of British Columbia, Vancouver, BC, Canada V6T 1Z4 \\ ${ }^{12}$ Neonatal Follow-Up Program, Children's and Women's Health Center of B.C., Vancouver, BC, Canada V6H 3V4 \\ ${ }^{13}$ Department of Public Health Sciences, University of Alberta, Edmonton, AB, Canada T6G 2T4 \\ ${ }^{14}$ Pediatric Cardiology, Alberta Children's Hospital, Calgary, AB, Canada T3B 6A8 \\ ${ }^{15}$ Section of Pediatric Cardiology, Children's Hospital of Winnipeg, Winnipeg, MB, Canada R3E 0Z2 \\ ${ }^{16}$ Developmental Follow-Up Clinic, Regina General Hospital, Regina, SK, Canada S7N OW8 \\ ${ }^{17}$ Division of Pediatric Cardiology, Royal University Hospital, Saskatoon, SK, Canada S7N OW8 \\ ${ }^{18}$ Division of Pediatric Cardiology, Stollery Children's Hospital, Edmonton, AB, Canada T6G 2B7 \\ ${ }^{19}$ Division of Pediatric Cardiology, Children's and Women's Health Center of B.C., Vancouver, BC, Canada V6H 3V4 \\ ${ }^{20}$ Department of Surgery, University of Alberta, Edmonton, AB, Canada T6G $2 B 7$
}

Correspondence should be addressed to Charlene M. T. Robertson, charlene.robertson@albertahealthservices.ca

Received 15 December 2010; Revised 15 February 2011; Accepted 25 February 2011

Academic Editor: Jeffrey P. Jacobs

Copyright ( $\odot 2011$ Charlene M. T. Robertson et al. This is an open access article distributed under the Creative Commons Attribution License, which permits unrestricted use, distribution, and reproduction in any medium, provided the original work is properly cited.

Newly emerging health technologies are being developed to care for children with complex cardiac defects. Neurodevelopmental and childhood school-related outcomes are of great interest to parents of children receiving this care, care providers, and healthcare administrators. Since the 1970s, neonatal follow-up clinics have provided service, audit, and research for preterm infants as care for these at-risk children evolved. We have chosen to present for this issue the mechanism for longitudinal follow-up of survivors that we have developed for western Canada patterned after neonatal follow-up. Our program provides registration for young children receiving complex cardiac surgery, heart transplantation, ventricular assist device support, and extracorporeal life support among others. The program includes multidisciplinary assessments with appropriate neurodevelopmental intervention, active quality improvement evaluations, and outcomes research. Through this mechanism, consistently high (96\%) follow-up over two years is maintained. 


\section{Introduction}

Neonatal and early childhood survivors of life-saving therapies including complex cardiac surgery and heart transplantation are at risk for neurodevelopmental sequelae. Possible determinants are brain injury $[1,2]$, complications of early gestational age birth or associated genetic abnormalities [37], prolonged and recurrent hospitalizations [8], and in some cases, a void of experiences available to other children $[9,10]$. The risk factors associated with adverse outcomes are multifactorial [11-14]. Enhanced understanding is emerging about patterns of health and neurodevelopmental outcome with focus on cognition, attention, motor skills, behavior, adaptive abilities, functional outcomes, health-related quality of life, and parental stress research $[9,10,15-20]$. This valuable information can assist in counselling parents of children needing specific procedures. In addition, combined with detailed acute care databases, this information can identify potentially modifiable predictors of outcome and evaluate part or all of the systems of care for a given therapy [21].

For more than 30 years, neonatal follow-up clinics have provided multidisciplinary assessments of high-risk neonates [22]. These clinics have the framework, experience, and expertise to complete long-term follow-up of at-risk children [23]. Most neonatal follow-up clinics provide neurodevelopmental assessments and have a mission of service to the child and family, as well as audit and research. Such service may be initiated by the program or through appropriate referrals. Individualized intervention may include nutritional therapy, physical therapy, occupational therapy, speech-language therapy, assessment and treatment of hearing loss, psychological interventions, social work support, and/or medical treatments. Group developmental intervention programs may be community based or tertiary care based. Key to the work of a neonatal follow-up clinic is the mission of audit [22]. Neurodevelopmental morbidity outcomes are linked to acute care variables to provide a basis for quality improvement as well as population trends. Various types of research facilitated through neonatal follow-up clinics include specific, local, and multicentered outcome studies as well as multicentered randomized controlled trials [22]. These clinics provide a setting for teaching trainees and interaction among all disciplines interested in the welfare of the high-risk infant [22]. Neonatal follow-up clinics are closely linked to neonatal intensive care but may be located in general or pediatric hospitals, or rehabilitation facilities. Many neonatal follow-up clinics now have extended entry criteria to include ill neonates beyond preterm children and some see children whose therapy occurred after the neonatal period [21]. Assessment guidelines for high-risk neonates have been published $[24,25]$.

This paper presents the organization of the Registry and Follow-up of Complex Pediatric Therapies Program of Western Canada which is based on the neonatal follow-up clinic model. This registry has been successful in the followup of infants and young children surviving life-threatening illnesses treated with newly emerging health technologies, identifying modifiable variables at each level of care, building a quality improvement program, and publishing outcomes research while providing a range of services for survivors with neurodevelopmental sequelae.

\section{Methods}

This is an interprovincial longitudinal neurodevelopmental follow-up program that began in 1999 for children from the western provinces of Canada and corresponding northern territories who have had invasive complex therapies in Alberta, Canada. The majority of procedures including complex cardiac surgery are done at the Stollery Children's Hospital, Edmonton, Alberta, Canada. The program evolved over the period from 1996 to 1999 beginning with a specif-ic research study on neurodevelopmental follow-up after complex cardiac surgery done at $\leq 6$ weeks of age and published in 2004 [26].

2.1. Organization. Program members include representatives of acute care departments including, cardiology, cardiovascular surgery, nephrology, hepatology/gastroenterology, and neonatal and pediatric intensive care in the province of Alberta as well as members from these specialities from participating sites across western Canada. Follow-up occurs at six sites. Follow-up team members including paediatricians with expertise in neurodevelopmental follow-up, psychologists, and audiologists are part of the membership. There is a direct liaison with healthcare administration at each site. A steering committee consists of the cochairs (a neurodevelopmental pediatrician, pediatric intensivist, and neonatal developmental follow-up/intensivist) and membership from the acute care departments. There are three standing subcommittees within the steering committee: data entry, retrieval, and linkage; outcome measurements; evaluation. Enrolment criteria are determined through the work of the core steering committee and individual departments.

Following a research study from 1996 to 1999 [26], a project grant was obtained from the provincial government for the period from 1999 to 2006 to determine healthcare outcomes of emerging technologies. Since 2006, the program has been part of the global budget at all sites to varying degrees with respective accountability.

\section{Procedure}

Referrals for follow-up are made by the attending physician within each acute care department based on predetermined entry criteria. Once survival is deemed likely, a nurse coordinator registers the child and discusses follow-up procedures with the parents. As parents become involved in the followup registration process, they come to understand the dual purpose of follow-up to include service for possible developmental concerns for their child and parental psychosocial support as well as an audit of outcomes of new complex therapies. Contact is made with the follow-up clinic at the tertiary site of origin. The project is approved by local health research ethics boards. All parents/guardians sign informed consent for follow-up and participation in the database. 
Databases were established for children needing each of the listed therapies. Acute care variables were chosen and modified by the cochairs and representatives of each department, and data are recorded prospectively by a program assistant. Outcome variables are standardized age appropriate, and uniform at all sites. Once compiled, anonymous data are returned to the central site for checking with a hard copy of the assessment results and for keying. All data entry is checked by one of the cochairs. SPSS, version 17 , is currently used for data storage and SPSS and SAS are used for analyses.

3.1. Assessments. At hospital discharge, we record specific acute measures and any underlying conditions that may ultimately affect the outcome of the child. Birth head circumference and head circumference at discharge are recorded as has been previously published for children after hypoxic-ischemic encephalopathy [27]. Information on genetic abnormalities or dysmorphic features, antenatal infections, and maternal substance abuse are recorded. Any available cranial imaging information is recorded as has been recommended [28]. Birth prevalence for the various defects may vary by year, location, race, and socioeconomic levels [29] thus information on year, locale, race [30], and socioeconomic levels [31] are completed.

Prior to the first follow-up assessment, records concerning the visual awareness of the child, including ophthalmological reports, formal hearing test results as have been recommended for at-risk children, [32] and recorded observations of feeding and swallowing by an experienced nurse or therapist are obtained. The latter includes specific concerns for airway anomalies in children with congenital heart disease which may subsequently interfere with the child's health and development [33]; information on facial hypotonia, a common difficulty for ill children, often addressed with positioning and feeding suggestions; incoordination or absent swallowing requiring alternate feeding methods with sensory lip and mouth stimulation by a feeding therapist [34]. Any concerns about the vulnerable child syndrome and its consequences for the child's social, emotional, and behavioural growth are recorded [35].

3.2. Measures. Timelines and approach to the long-term follow-up are similar to published guidelines [24, 25]. Measures include assessment, rating, or screening tools. The focus of the assessment at each age is to assist in providing service for children to reduce impact on limitations of function, activities, and participation as recommended using the WHO International Classification of Function [36]. Outcome measures are standardized, and the latest edition is used. Overall, test batteries appropriate for age measure neurodevelopment, intellectual function, attention, memory and learning, language, behavior, motor function, and hearing, as well as neurological examination (Table 1).

\section{Statistical Analysis}

Kaplan-Meier survival curves with log-rank test are used to compare cumulative survival across several groups. Continuous outcomes of morbidity are presented as means (SD); categorical variables are presented as counts and percentages. To screen for variables associated with outcomes, univariate regression models are used. Multiple regression models are built based on variables significant at $P<.10$ in the corresponding univariate analysis, and after screening for multicollinearity. The type of outcome drives the choice of the regression model and presentation of results, for example, linear regression is used for continuous outcomes and results are presented as effect sizes, logistic regression is used for dichotomous variables and results are presented as odds ratios, and the Cox proportional hazard model is used for survival data, and results are presented as hazard ratios. All estimates are presented together with confidence intervals and two-sided $P$ values.

When testing several outcomes, one should adjust for multiple comparisons. The larger the number of outcomes tested, the more inflated the Type I error. Bonferroni type adjustments are made in such situations.

\section{Results}

Since 1996, over 1000 children have been registered with this follow-up program. This includes 659 children following complex cardiac surgery done at age $\leq 6$ weeks (Table 2), 11 children after chronic renal dialysis in the first year of life, 175 children after solid organ transplantation done at age 5 years or less (61 heart, 97 liver, 17 kidney), 153 children after extracorporeal life support given at age 5 years or less (109 cardiac, 44 pulmonary), 21 children with ventricular assist devices at age 5 years or less, and 16 children following cooling after in-hospital cardiopulmonary resuscitation done at age 5 years or less. Follow-up at two years is $>96 \%$ (Figure 1).

5.1. Service. The Registry and Follow-up of Complex Pediatric Therapies Program has benefited children receiving emerging health technologies in our region. Assessments and interventions can make a significant improvement in the child's ultimate quality of life $[52,53]$. With early recognition of developmental delay and family support to promote the child's motivation and learning, the child's long-term outcome is improved. There are few children undergoing these rare-event therapies: in our region, they would typically not receive early intervention and early education without the follow-up clinic outcome assessments directing the family to the appropriate program (Table 3 ). Our follow-up program has a strong advocacy role for children and provides an added value service to the child and family while obtaining outcome data. The educational system benefits from having the children more prepared for learning at school entry and having knowledge about specific learning patterns of the survivors.

Knowledge of the risk, safety, and outcome of care for life-threatening illness enables acute care practitioners to discuss, from a stronger evidence base, the potential outcomes for children undergoing these therapies. Parents become more familiar with the process and begin to understand the life-saving procedures as only one step in the overall system 
TABLE 1: Disciplines that assess and measures used for neurodevelopmental and neurocognitive follow-up after complex cardiac surgery at $\leq 6$ weeks of age.

\begin{tabular}{|c|c|c|}
\hline Follow-up age & $\begin{array}{l}\text { Disciplines } \\
\text { assessing }\end{array}$ & Specific tests required for outcomes \\
\hline $\begin{array}{l}6 \text { to } 8 \text { months after } \\
\text { surgery/therapy }\end{array}$ & $\begin{array}{l}\text { Physical therapist* } \\
\text { Audiologist** } \\
\text { Physician/nurse }\end{array}$ & \\
\hline $\begin{array}{l}18 \text { to } 24 \text { months } \\
\text { (range } 18-36 \text { months) }\end{array}$ & $\begin{array}{l}\text { Psychologist } \\
\text { Audiologist** } \\
\text { Speech-language } \\
\text { pathologist* } \\
\text { Physician/nurse*** }\end{array}$ & $\begin{array}{l}\text { Bayley Scales of Infant and Toddler Development-3rd Edition. All } \\
\text { components include Cognitive Scale, Language Scale (receptive and expressive } \\
\text { language), Motor Scale (fine and gross motor), Social-Emotional Scale, and } \\
\text { Adaptive Behavior Scale [37]. } \\
\text { Child Behavior Checklist with Language } \\
\text { Development Survey [38]. }\end{array}$ \\
\hline $\begin{array}{l}4.3 \text { to } 5.5 \text { years } \\
\text { (range } 4-6 \text { years) }\end{array}$ & $\begin{array}{l}\text { Psychologist } \\
\text { Audiologist** } \\
\text { Speech-language } \\
\text { pathologist } \\
\text { Physician/nurse*** }\end{array}$ & $\begin{array}{l}\text { Wechsler Preschool and Primary Scale of Intelligence-3rd Edition [39]. } \\
\text { Visual Motor Integration-5th Edition [40]. } \\
\text { Behavior Assessment System for Children-2nd Edition [41]. } \\
\text { Adaptive-Behavior Assessment System-2nd Edition [42]. } \\
\text { Pediatric Quality of Life Inventory, Generic Core Scales [43], and Cardiac } \\
\text { Module [44]. } \\
\text { Clinical Evaluation of Language Fundamentals—2nd Edition [45]. }\end{array}$ \\
\hline $\begin{array}{l}8 \text { years } \pm 6 \text { months (range } \\
6.5 \text { years to } 16 \text { y } 11 \text { months) } \\
\text { selectively for children with } \\
\text { single ventricle defects, } \\
\text { heart transplantation, } \\
\text { extracorporeal membrane } \\
\text { oxygenation }\end{array}$ & $\begin{array}{l}\text { Psychologist } \\
\text { Audiologist** }^{* *} \\
\text { Physician/Nurse }\end{array}$ & $\begin{array}{l}\text { Wechsler Intelligence Scale for Children-4th Edition [46]. } \\
\text { Visual Motor Integration-5th Edition [40]. } \\
\text { Wechsler Individual Achievement Test-2nd Edition [47]. } \\
\text { NEPSY-2nd Edition [48]. } \\
\text { Adaptive Behavior Assessment System-2nd Edition [42]. } \\
\text { Behavior Rating Inventory of Executive Function Parent Form [49]. } \\
\text { Child and Adolescent Scale of Participation [50]. } \\
\text { Strength and Difficulties Questionnaire [51]. } \\
\text { Pediatric Quality of Life Inventory, Generic Core Scales [43]. }\end{array}$ \\
\hline
\end{tabular}

* Clinical assessment, no data collection. Measures individually determined.

** Standard audiological assessment for at-risk children [32].

***At each visit, the pediatrician and nurse complete a predetermined questionnaire about illnesses and hospitalizations as well as diet, feeding, sleep, immunizations, and parent support; record growth; complete a general and neurological examination. If required, other disciplines such as occupational therapist, dietician, or social worker assesses the child/family.

TABLE 2: Type of complex cardiac surgery at $\leq 6$ weeks of age in relation to grouped years of surgery: 1996-2010.

\begin{tabular}{|c|c|c|c|c|c|}
\hline Years & $\begin{array}{c}\text { Total } \\
n=659\end{array}$ & $\begin{array}{c}\text { ASO } \\
n=188\end{array}$ & $\begin{array}{c}\text { Norwood for HLHS } \\
n=146\end{array}$ & $\begin{array}{l}\text { TAPVC } \\
n=81\end{array}$ & $\begin{array}{c}\text { Other } \\
n=244\end{array}$ \\
\hline 1996-1999 & $92(14 \%)$ & $28(15 \%)$ & $25(17 \%)$ & $9(11 \%)$ & $30(12 \%)(9 \mathrm{ca})$ \\
\hline 2000-2002 & $119(18 \%)$ & $35(19 \%)$ & $36(25 \%)(2 \mathrm{ca})$ & $19(23 \%)(1 \mathrm{ca})$ & $29(12 \%)(7 \mathrm{ca})$ \\
\hline 2003-2005 & $149(22 \%)$ & $51(27 \%)$ & $31(21 \%)(1 \mathrm{ca})$ & $20(25 \%)$ & $47(19 \%)(14 \mathrm{ca})$ \\
\hline 2006-2008 & $156(24 \%)$ & $42(22 \%)$ & $34(23 \%)$ & $20(25 \%)$ & $60(25 \%)(11 \mathrm{ca})$ \\
\hline 2009-2010 & $143(22 \%)$ & $32(17 \%)(1 \mathrm{ca})$ & $20(14 \%)$ & $13(16 \%)$ & $78(32 \%)(7 \mathrm{ca})$ \\
\hline
\end{tabular}

$\mathrm{ASO}=$ arterial switch operation.

HLHS = hypoplastic left heart syndrome.

TAPVC $=$ total anomalous pulmonary venous correction.

$\mathrm{ca}=$ chromosomal abnormalities.

Other by primary defect = pulmonary atresia, 52; interrupted aortic arch, 36; tetralogy of fallot, 34; truncus arteriosus, 32; double outlet right ventricle, 24; hypoplastic aortic Arch, 14; AV canal, 14; tricuspid atresia, 10; Other, 28.

Note: 52 (7.9\%) of 659 had chromosomal abnormalities.

of care. They become more knowledgeable regarding their child and have increased willingness for their child to benefit from early intervention and educational experiences. Parents are empowered to play a stronger advocacy role for their child to achieve the best outcome.
5.2. Quality Improvement/Research. Functional information from the Adaptive Behavioral Assessment System, second edition [42], helps us to give a description of the extent and range of functional limitations that children after complex cardiac surgery experience as they grow. This information 


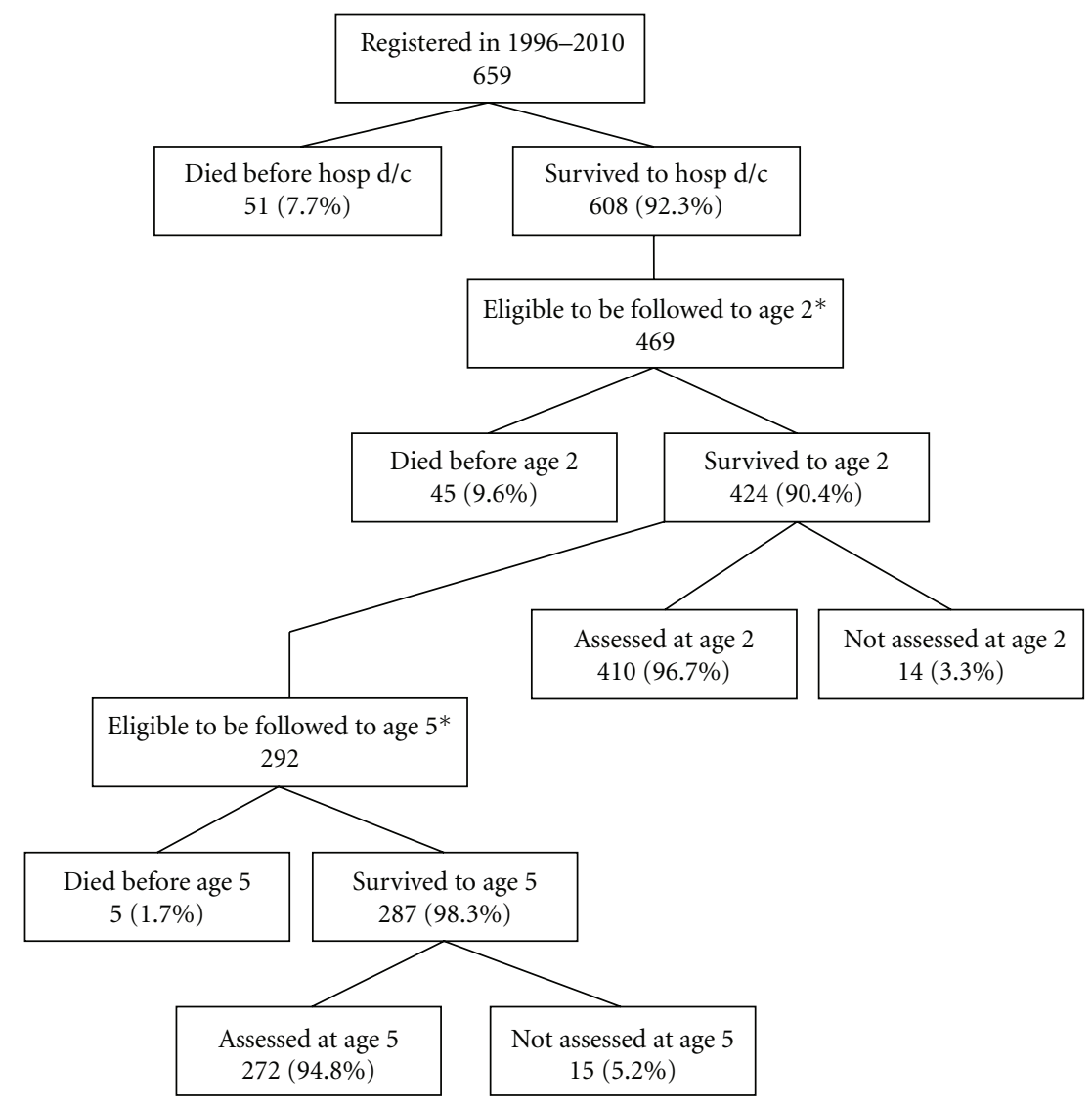

*139 children have not yet reached age 2 , and 132 children have not yet reached age 5 .

Figure 1: Flowchart of death, lost, and assessed children after complex cardiac surgery at $\leq 6$ weeks of age from the year 1996 to 2010 ; inclusive. hosp $\mathrm{d} / \mathrm{c}=$ discharge from hospital where surgery took place.

allows a proactive and dynamic approach to preparing parents with the challenges of raising children who have been very ill and gear interventions toward individual needs (Table 3).

Modifications in the type of assessments we administer and the focus of counselling have evolved based on our results (Table 3 ). In some cases, these results may not be generalizable but apply to our populations. By grouping outcome data and analyzing predictor acute care variables, we have identified potentially modifiable variables resulting in specific quality improvement evaluations (examples are provided in Table 3).

Our program has contributed to the outcomes literature following complex cardiac surgery for very young children in a number of ways (Tables 4-7). Serial lactate determination has been shown to predict survival [64]. Building on our early study [26], we completed a longitudinal study and confirmed that neurodevelopmental outcomes at two years of age for children after complex cardiac surgery are predictive of the neurocognitive outcomes at age five years [65]. The sensitivity and specificity of the mental developmental index scores under 85 for predicting the full-scale intelligence score at preschool were $85.7 \%$ and $89.7 \%$, respectively, indicating the value of testing children at younger ages.

We have published on the early childhood outcome following total anomalous pulmonary venous correction [60]. As an unexpected finding, we found that aboriginal children were markedly over represented in this group compared with the rest of our population. We have also published on the outcomes of children with interrupted aortic arch without chromosomal anomalies [66] and children with complex cardiac surgery in the neonatal period who have deletion 22q11.2 [7]. The latter are at a high risk for adverse neurodevelopmental outcomes. A recent paper of the twoyear neurodevelopmental outcomes of children following the Norwood right ventricle-to-pulmonary artery shunt surgical repair demonstrated improved survival and psychomotor developmental outcome over the previous Blalock-Taussig surgical era [58].

The findings of the follow-up program have justified the investment in several ways. We are one of few groups to describe the long-term neurodevelopmental outcome and general morbidity of many groups of cardiac diseases treated in the neonatal period (Tables 4 and 7). We have 
TABLE 3: Examples of audit and research findings resulting in changes in care for survivors following complex cardiac surgery at $\leq 6$ weeks of age.

\begin{tabular}{lll}
\hline Service delivery & Audit funding & Changes in care \\
\hline & \multicolumn{1}{c}{ General areas } & \\
\hline $\begin{array}{l}\text { Assessments by physical therapists, occupational } \\
\text { therapist, dieticians and speech-language } \\
\text { pathologists provided evidence of the needs of } \\
\text { survivors to site managers and to attending } \\
\text { physicians. }\end{array}$ & $\begin{array}{l}\text { Therapy and early developmental intervention as } \\
\text { needed is available from time of hospital } \\
\text { discharge at each site. }\end{array}$ \\
$\begin{array}{l}\text { Children's attending physicians are more aware of } \\
\text { the developmental needs of survivors and the } \\
\text { importance and benefit of early developmental } \\
\text { multidisciplinary } \\
\text { assessment clinics }\end{array}$ & $\begin{array}{l}\text { Therapists demonstrated the benefits of } \\
\text { multidisciplinary assessments of survivors to their } \\
\text { managers. }\end{array}$ & $\begin{array}{l}\text { Funding for follow-up clinics has become part of } \\
\text { the global budget for } 4 \text { of the } 6 \text { sites. }\end{array}$ \\
$\begin{array}{l}\text { Identification of areas for } \\
\text { focused developmental } \\
\text { intervention. }\end{array}$ & $\begin{array}{l}\text { Team assessments identified specific areas of } \\
\text { developmental concerns. }\end{array}$ & $\begin{array}{l}\text { Monitoring and developmental therapy } \\
\text { interventions have become proactive and more } \\
\text { focused to the specific needs of the child and } \\
\text { family. }\end{array}$ \\
& $\begin{array}{l}\text { Education and advocacy for developmental } \\
\text { community supports have resulted in improved } \\
\text { services for children and families. }\end{array}$
\end{tabular}

Specific neurodevelopmental areas

Functional development Delays have been demonstrated [10].

Speech-language
development

Social communication

Preschool behaviour

Cerebral palsy

Gross motor abilities

Pulmonary complications

Mean arterial pressure after
re-warming in the
operating room
Transfusion in neonates
undergoing the Norwood
operation

Extracorporeal life support

Language delay was noted after arterial-switch of the Language Developmental Survey of the Child Behaviour Checklist [38] (unpublished data).

Impairments were shown after arterial-switch operation [55].

For our survivors, behavioural concerns do not exceed those in the normative population [56]. survivors [57].

Delays have been demonstrated [58]. venous correction [60]. operation [54]. A high proportion of all survivors were noted to have delay on the vocabulary score

This is not a common complication among our

Common following total anomalous pulmonary

Specific acute care areas

Lower mean arterial pressure was associated with death [61].

Transfusion did not improve outcomes [62].

Time for lactate to fall and inotrope score are associated with outcome [63].
Involvement of our program staff with bedside developmental care, discharge planning, early developmental intervention, and parent education.

All survivors after early cardiac complex surgery are now assessed by a speech-language pathologist at the 2-year visit.

Children are monitored during the preschool period for language and social communication skills. Intervention is started as needed.

Counselling avoids suggestions of possible future adverse behaviour as this can become a self-fulfilling prophecy.

Counselling at the time of surgery based on imaging suggests monitoring without predicting cerebral palsy.

Clinic plan to add a standardized motor measure [59].

Consideration of additional routine referrals for pulmonary consultation.
Blood pressure control in the operating room has been changed.

Transfusion practices have been altered.

There is increased focus on the optimal cannula size and initial blood flow rates when patients are placed on extracorporeal life support. 
TABle 4: Selected outcomes of neonates having complex cardiac surgery for congenital heart disease followed by the Complex Pediatric Therapies Follow-up Program.

\begin{tabular}{|c|c|c|c|}
\hline Group (years, $n$ ) & 2-year survival & MDI (mean, SD) & PDI (mean, SD) \\
\hline ASO $(1996-2004 ; n=88)[54]$ & $99 \%$ & $89(17)$ & $92(15)$ \\
\hline TAPVC $(1996-2004 ; n=32)[60]$ & $97 \%$ & $87(16)$ & $89(13)$ \\
\hline Norwood MBTS $(1996-2002 ; n=62)[58]$ & $48 \%$ & $79(18)$ & $67(19)$ \\
\hline Norwood RVPA (2002-2005; $n=32)$ [58] & $81 \%$ & $85(18)$ & $78(18)$ \\
\hline IAA $(1996-2006 ; n=27)[66]$ & $96.5 \%$ & $76(17)$ & $72(17)$ \\
\hline Deletion22q11.2 (1996-2004; $n=16)[7]$ & $81 \%$ & $66(11)$ & $55(9)$ \\
\hline Cardiac ECLS (2002-2004; $n=39)$ [63] & $41 \%$ & $73(16)$ & - \\
\hline E-CPR subgroup $(n=9)$ & $33 \%$ & - & - \\
\hline Heart transplant under age 6 yr $(1999-2006 ; n=33)[67]$ & $88 \%$ & Delay $34 \%$ & Delay $52 \%$ \\
\hline
\end{tabular}

ASO: arterial switch operation for transposition of the great arteries; TAPVC: total anomalous pulmonary venous correction; MBTS: modified Blalock-Taussig shunt; RVPA: right ventricle-to-pulmonary artery shunt; IAA: correction of interrupted aortic arch; ECLS: extracorporeal life support; E-CPR: ECLS started during ongoing chest compressions for refractory cardiac arrest; MDI: Mental Developmental Index; PDI: Psychomotor Developmental Index.

TABLE 5: Variables found associated with outcomes of specific groups of neonates having complex cardiac surgery for congenital heart disease followed by the Complex Pediatric Therapies Follow-up Program.*

\begin{tabular}{|c|c|c|c|}
\hline Group (years, $n$ ) & Associated with survival & Associated with MDI & Associated with PDI \\
\hline ASO $(1996-2004 ; n=88)[54]$ & - & \multicolumn{2}{|c|}{ EGA, preoperative lactate and days ventilated, days in hospita } \\
\hline $\begin{array}{l}\text { ASO (1996-2003; } n=65 \\
5 \text {-year outcomes of FSIQ) [55] }\end{array}$ & - & \multicolumn{2}{|c|}{ Mother's years of schooling, EGA, postoperative d1 lactate } \\
\hline $\begin{array}{l}\text { TAPVC }(1996-2004 ; n=32) \\
{[60]}\end{array}$ & - & SES & $\begin{array}{l}\text { Weight at surgery, } \\
\text { postoperative d1 lactate }\end{array}$ \\
\hline $\begin{array}{l}\text { Norwood MBTS (1996-2002; } \\
n=62)[58]\end{array}$ & $\begin{array}{c}\text { Postoperative d2-5 lactate } \\
\text { and base deficit }\end{array}$ & SES, hospital days & Sex \\
\hline $\begin{array}{l}\text { Norwood RVPA (2002-2005; } \\
n=32)[58]\end{array}$ & Postoperative d2-5 lactate & $\begin{array}{l}\text { Preoperative } \mathrm{PaO2} \text { and } \\
\text { days ventilated, } \mathrm{DHCA} \\
\text { time }\end{array}$ & $\begin{array}{l}\text { CPR anytime, hospital } \\
\text { days }\end{array}$ \\
\hline $\begin{array}{l}\text { Norwood }(1996-2005, \text { no } \\
\text { ECLS, } n=82)[62]\end{array}$ & $\begin{array}{l}\text { Postoperative d2-5 nadir } \\
\text { haemoglobin level }\end{array}$ & $\begin{array}{l}\text { First postoperative day } \\
\text { of negative fluid balance }\end{array}$ & $\begin{array}{l}\text { Sex, first postoperative } \\
\text { day of negative fluid } \\
\text { balance }\end{array}$ \\
\hline IAA $(1996-2006 ; n=27)[66]$ & - & $\begin{array}{l}\text { Chromosomal } \\
\text { abnormality, Apgar } \\
\text { score, DHCA used }\end{array}$ & $\begin{array}{l}\text { Chromosomal } \\
\text { abnormality }\end{array}$ \\
\hline $\begin{array}{l}\text { Cardiac ECLS (2002-2004; } \\
n=39)[63]\end{array}$ & $\begin{array}{c}\text { Single ventricle, lactate } \\
\text { on admission, days } \\
\text { ventilated }\end{array}$ & $\begin{array}{c}\text { Chromosomal } \\
\text { abnormality, time for } \\
\text { lactate to fall on ECLS, } \\
\text { highest inotrope score first } \\
5 \text { d on ECLS }\end{array}$ & - \\
\hline $\begin{array}{l}\text { Heart transplant (1999-2006; } \\
n=33)[67]\end{array}$ & Congenital heart disease & Congenital heart disease & Congenital heart disease \\
\hline
\end{tabular}

ASO: arterial switch operation for transposition of the great arteries; TAPVC: total anomalous pulmonary venous correction; MBTS: modified BlalockTaussig shunt; RVPA: right ventricle-to-pulmonary artery shunt; IAA: correction of interrupted aortic arch; ECLS: extracorporeal life support; E-CPR: ECLS started during ongoing chest compressions for refractory cardiac arrest; EGA: early gestational age; MDI: Mental Developmental Index; PDI: Psychomotor Developmental Index; * Variables that are potentially modifiable are in italicized font.

found several potentially modifiable acute care variables with the potential to improve outcomes of these neonates with each cardiac disease (Table 5). In addition, we have been able to examine specific potentially modifiable variables that have been of great interest in the literature, including blood pressure, transfusions, lactate, sedation, and CPR, for their association with outcome (Table 6). These findings have led to improved counselling of parents, improved long-term care, and changes in acute care that have great potential to improve outcomes (Table 3 ). Continued followup informs whether these outcomes are improving over time; for example, we found that the outcome of HLHS children has improved significantly between two surgical eras [58]. 
TABLE 6: Some specific variables examined for association with outcomes of neonates having complex cardiac surgery for congenital heart disease followed by the Complex Pediatric Therapies Follow-up Program.

\begin{tabular}{|c|c|}
\hline Variable examined (years, $n$ ) & Effect on outcomes \\
\hline Postoperative lactate $(1996-1999 ; n=85)[64]$ & $\begin{array}{l}\text { Associated with mortality; lactate } \geq 7 \mathrm{mmol} / \mathrm{L} \text { on admission, } \\
\text { and d } 1 \text { peak } \geq 8 \mathrm{mmol} / \mathrm{L} \text { : sensitivity } 83 \% \text {, specificity } 82 \% \text {. }\end{array}$ \\
\hline $\begin{array}{l}\text { MAP after re-warming in the operating room (1996-1999; } \\
n=70)[61]\end{array}$ & $\begin{array}{l}\text { Associated with mortality by } 5 \text { years of age: minutes MAP } \leq \\
30 \mathrm{mmHg} \text { odds ratio } 1.09 \text { ( } 95 \% \text { CI } 1.03,1.16) .\end{array}$ \\
\hline Transfusion in Norwood Group $(1996-2005 ; n=82)$ [62] & $\begin{array}{l}\text { Associated with ventilator days postoperatively: postoperative } \\
\text { number of transfusions d2-5 effect size } 1.85(0.33,3.36) \text { days. }\end{array}$ \\
\hline Postoperative CPR $(1996-2005 ; n=29)[68]$ & $\begin{array}{l}\text { Associated with mortality by } 2 \text { years (odds ratio } 15.02,95 \% \text { CI } \\
4.63,48.76 \text { ), but not neurodevelopmental outcome in survivors. }\end{array}$ \\
\hline $\begin{array}{l}\text { Perioperative sedation (benzodiazepines, opiates, chloral hydrate, } \\
\text { ketamine, inhalational agents; 2003-2006; } n=95 \text { ) [69] }\end{array}$ & $\begin{array}{l}\text { No evidence of an association with neurodevelopmental } \\
\text { outcomes. }\end{array}$ \\
\hline Deletion 22q11.2 (1996-2004; $n=16)$ [7] & Associated with MDI and PDI. \\
\hline
\end{tabular}

MAP: mean arterial pressure: CPR: cardiopulmonary resuscitation; MDI: Mental Developmental Index; PDI: Psychomotor Developmental Index.

TABLE 7: Selected outcomes of neonates having complex cardiac surgery for congenital heart disease followed by the Complex Pediatric Therapies Follow-up Program.

\begin{tabular}{|c|c|c|c|c|}
\hline Group (years, $n$ ) & Microcephaly & Weight $<5$ th percentile & Height $<5$ th percentile & Cerebral palsy \\
\hline ASO $(1996-2004 ; n=88)[54]$ & $1.5 \%$ & $6.1 \%$ & $9.8 \%$ & $1.2 \%$ \\
\hline TAPVC $(1996-2004 ; n=32)[60]$ & $0 \%$ & $3 \%$ & $0 \%$ & $0 \%$ \\
\hline Norwood MBTS (1996-2002; $n=62)$ [58] & $7 \%$ & $17 \%$ & $20 \%$ & $0 \%$ \\
\hline Norwood RVPA (2002-2005; $n=32)$ [58] & $0 \%$ & $27 \%$ & $12 \%$ & $4 \%$ \\
\hline IAA $(1996-2006 ; n=27)[66]$ & $7.7 \%$ & $19 \%$ & $19 \%$ & - \\
\hline Deletion 22q11.2 (1996-2004; $n=16)$ [7] & $15 \%$ & $8 \%$ & $31 \%$ & - \\
\hline Cardiac ECLS (2002-2004; $n=39)[63]$ & $20 \%$ & $19 \%$ & $13 \%$ & $13 \%$ \\
\hline Heart transplant under age 6 yr $(1999-2006 ; n=29)[67]$ & - & $28 \%$ & $31 \%$ & $10 \%$ \\
\hline
\end{tabular}

ASO: arterial switch operation for transposition of the great arteries; TAPVC: total anomalous pulmonary venous correction; MBTS: modified Blalock-Taussig shunt; RVPA: right ventricle-to-pulmonary artery shunt; IAA: correction of interrupted aortic arch; ECLS: extracorporeal life support.

\section{Discussion}

We have chosen to present the organization of the Registry and Follow-up of Complex Pediatric Therapies Program to demonstrate a mechanism for longitudinal follow-up. Using the model of neonatal follow-up clinics, we have established a longitudinal follow-up program in western Canada for children receiving new and emerging therapies in Alberta and particularly for those receiving complex cardiac surgery as very young children at the Stollery Children's Hospital in Edmonton. By linking with the neonatal follow-up clinics, we have been able to use their expertise to maintain a high proportion of follow-up and establish an ongoing and interactive database. This database has been valuable to establish quality improvement studies and outcomes research as has been recommended [70].

Several areas of change have been initiated as a result of the findings of our follow-up program (detailed in Table 3). Examples in general areas include improved timely access to developmental intervention, enhanced funding for demonstrably needed multidisciplinary assessment clinics, and improved proactive advocacy for these children. Examples in specific areas include: improved early intervention and parent education regarding impaired functional development, standard speech-language pathologist assessment, and monitoring for language and social communication skills. Examples in acute care areas include: improved blood pressure control in the operating room, altered transfusion practices in single ventricle neonates, and improved management of neonates requiring extracorporeal life support. Ongoing follow-up will identify if these quality improvement interventions have been associated with improved outcomes in these neonates. In addition, the data from our follow-up group is now being used to inform design of prospective randomized trials of interventions.

We believe the key to the work we have done is based on the interaction between service for the child and family and the study of outcomes. This provides an opportunity to enhance the quality of care that we, as healthcare professionals, provide and enables us to minimize secondary developmental disabilities.

This longitudinal follow-up program is now established as part of the care of new and emerging therapies in Alberta and for children transferred to this province for this care. We are very grateful to the hospitals, clinics, and parents who cooperate to make this possible. Our 
attrition rate is low, under $4 \%$ over 2 years, and similar to other follow-up programs in western Canada. We have documented outcomes to aid in the counselling of parents of newly referred children needing these therapies. Some novel findings have been reported. Potentially modifiable variables have been identified that can influence acute care practices. Most importantly, we are providing a needed service to the children following these life-saving therapies.

\section{Acknowledgments}

The authors are deeply indebted to the children and parents attending follow-up for their consistent willingness to travel long distances and participate in our program. The authors thank Jill T. Tomlinson, CHIM, data information analyst, for her precise handling of the large volume of information within this program. Financial support was provided for the Registry and Follow-up of Complex Pediatric Therapies Project by Alberta Health and Wellness with ongoing support from the Stollery Children's Hospital, Edmonton, Alberta, Canada.

\section{References}

[1] A. J. Du Piessis, "Mechanisms of brain injury during infant cardiac surgery," Seminars in Pediatric Neurology, vol. 6, no. 1, pp. 32-47, 1999.

[2] S. P. Miller, P. S. McQuillen, S. Hamrick et al., "Abnormal brain development in newborns with congenital heart disease," New England Journal of Medicine, vol. 357, no. 19, pp. 1928-1938, 2007.

[3] J. W. Gaynor, G. Wernovsky, G. P. Jarvik et al., "Patient characteristics are important determinants of neurodevelopmental outcome at one year of age after neonatal and infant cardiac surgery," Journal of Thoracic and Cardiovascular Surgery, vol. 133, no. 5, pp. 1344-1353, 2007.

[4] J. W. Gaynor, M. Gerdes, E. H. Zackai et al., “Apolipoprotein E genotype and neurodevelopmental sequelae of infant cardiac surgery," Journal of Thoracic and Cardiovascular Surgery, vol. 126, no. 6, pp. 1736-1745, 2003.

[5] S. Dimmick, K. Walker, N. Badawi et al., "Outcomes following surgery for congenital heart disease in low-birthweight infants," Journal of Paediatrics and Child Health, vol. 43, no. 5, pp. 370-375, 2007.

[6] E. Goldmuntz, "The genetic contribution to congenital heart disease," Pediatric Clinics of North America, vol. 51, no. 6, pp. 1721-1737, 2004.

[7] J. Atallah, A. R. Joffe, C. M. T. Robertson, N. Leonard, P. M. Blakley, and A. Nettel-Aguirre, "Two-year general and neurodevelopmental outcome after neonatal complex cardiac surgery in patients with deletion 22q11.2: a comparative study," Journal of Thoracic and Cardiovascular Surgery, vol. 134, no. 3, pp. 772-779, 2007.

[8] J. W. Newburger, D. Wypij, D. C. Bellinger et al., "Length of stay after infant heart surgery is related to cognitive outcome at age 8 years," Journal of Pediatrics, vol. 143, no. 1, pp. 67-73, 2003.

[9] G. R. Rempel, M. J. Harrison, and D. L. Williamson, "Is "Treat your child normally" helpful advice for parents of survivors of treatment of hypoplastic left heart syndrome?" Cardiology in the Young, vol. 19, no. 2, pp. 135-144, 2009.
[10] G. Y. Alton, G. R. Rempel, C. M. T. Robertson, C. V. Newburn-Cook, and C. M. Norris, "Functional outcomes after neonatal open cardiac surgery: comparison of survivors of the Norwood staged procedure and the arterial switch operation," Cardiology in the Young, vol. 20, no. 6, pp. 668-675, 2010.

[11] G. Wernovsky, A. J. Shillingford, and J. W. Gaynor, "Central nervous system outcomes in children with complex congenital heart disease," Current Opinion in Cardiology, vol. 20, no. 2, pp. 90-99, 2005.

[12] M. Miatton, D. De Wolf, K. François, E. Thiery, and G. Vingerhoets, "Neurocognitive consequences of surgically corrected congenital heart defects: a review," Neuropsychology Review, vol. 16, no. 2, pp. 65-85, 2006.

[13] A. J. Shillingford and G. Wernovsky, "Academic performance and behavioral difficulties after neonatal and infant heart surgery," Pediatric Clinics of North America, vol. 51, no. 6, pp. 1625-1639, 2004.

[14] G. Wernovsky, "Current insights regarding neurological and developmental abnormalities in children and young adults with complex congenital cardiac disease," Cardiology in the Young, vol. 16, supplement 1, pp. 92-104, 2006.

[15] J. W. Newburger, A. R. Silbert, L. P. Buckley, and D. C. Fyler, "Cognitive function and age at repair of transposition of the great arteries in children," New England Journal of Medicine, vol. 310, no. 23, pp. 1495-1499, 1984.

[16] A. J. Shillingford, M. M. Glanzman, R. F. Ittenbach, R. R. Clancy, J. W. Gaynor, and G. Wernovsky, "Inattention, hyperactivity, and school performance in a population of schoolage children with complex congenital heart disease," Pediatrics, vol. 121, no. 4, pp. e759-e767, 2008.

[17] H. H. Hövels-Gürich, M. C. Seghaye, S. Dabritz, B. J. Messmer, and G. Von Bernuth, "Cognitive and motor development in preschool and school-aged children after neonatal arterial switch operation," Journal of Thoracic and Cardiovascular Surgery, vol. 114, no. 4, pp. 578-585, 1997.

[18] D. C. Bellinger, J. W. Newburger, D. Wypij, K. C. K. Kuban, A. J. du Plesssis, and L. A. Rappaport, "Behaviour at eight years in children with surgically corrected transposition: the Boston Circulatory Arrest Trial," Cardiology in the Young, vol. 19, no. 1, pp. 86-97, 2009.

[19] J. H. Kern, V. J. Hinton, N. E. Nereo, C. J. Hayes, and W. M. Gersony, "Early developmental outcome after the norwood procedure for hypoplastic left heart syndrome," Pediatrics, vol. 102, no. 5, pp. 1148-1152, 1998.

[20] A. Majnemer, C. Limperopoulos, M. I. Shevell, C. Rohlicek, B. Rosenblatt, and C. Tchervenkov, "A new look at outcomes of infants with congenital heart disease," Pediatric Neurology, vol. 40, no. 3, pp. 197-204, 2009.

[21] R. Sauve and C. M. T. Robertson, "Follow-up of children who received complex invasive therapies early in life," Paediatrics and Child Health, vol. 11, no. 5, pp. 287-290, 2006.

[22] R. Sauve and S. K. Lee, "Neonatal follow-up programs and follow-up studies: historical and current perspectives," Paediatrics and Child Health, vol. 11, no. 5, pp. 267-270, 2006.

[23] A. R. Synnes, F. Lefebvre, and H. A. Cake, "Current status of neonatal follow-up in Canada," Paediatrics and Child Health, vol. 11, no. 5, pp. 271-274, 2006.

[24] The American Academy of Pediatrics, "Follow-up care of high-risk infants," Pediatrics, vol. 114, pp. 1377-1397, 2004.

[25] G. Cioni and E. Mercui, Neurological Assessment in the First Two Years of Life: Instruments for the Follow-Up of High Risk Newborns. Clinics in Developmental Medicine, vol. 176, MacKeith Press, London, UK, 2007. 
[26] C. M. T. Robertson, A. R. Joffe, R. S. Sauve et al., "Outcomes from an interprovincial program of newborn open heart surgery," Journal of Pediatrics, vol. 144, no. 1, pp. 86-92, 2004.

[27] C. M. T. Robertson, "Long-term follow-up of term infants with perinatal asphyxia," in Fetal and Neonatal Brain Injury: Mechanisms, Management and the Risk of Practice, B. K. Stevenson, W. E. Benitz, and P. Sunshine, Eds., pp. 829858, Cambridge University Press, Cambridge, UK, 3rd edition, 2003.

[28] W. T. Mahle, F. Tavani, R. A. Zimmerman, S. C. Nicholson, K. K. Galli, and J. W. Gaynor, "An MRI study of neurological injury before and after congenital heart disease," Circulation, vol. 106, supplement 1, pp. I-109-I-114, 2002.

[29] C. Wren, S. Richmond, and L. Donaldson, "Temporal variability in birth prevalence of cardiovascular malformations," Heart, vol. 83, no. 4, pp. 414-419, 2000.

[30] NIH policy of reporting race and ethnicitydata: subjects in clinical research, 2006, http://grants.nih.gov/grants/guide/ notice-files/not-od-01-053.html.

[31] B. R. Blishen, W. K. Carroll, and C. Moore, "The 1981 socioeconomic index for occupations in Canada," Canadian Review of Sociology \& Anthropology, vol. 24, no. 4, pp. 465488, 1987.

[32] J. Busa, J. Harrison, J. Chappell et al., "2007 position statement: principles and guidelines for early hearing detection and intervention programs," Pediatrics, vol. 120, no. 4, pp. 898921, 2007.

[33] J. P. Guillemaud, H. El-Hakim, S. Richards, and N. Chauhan, "Airway pathologic abnormalities in symptomatic children with congenital cardiac and vascular disease," Archives of Otolaryngology, vol. 133, no. 7, pp. 672-676, 2007.

[34] S. M. Schwarz, J. Corredor, J. Fisher-Medina, J. Cohen, and S. Rabinowitz, "Diagnosis and treatment of feeding disorders in children with developmental disabilities," Pediatrics, vol. 108, no. 3, pp. 671-676, 2001.

[35] M. Thomasgard and W. P. Metz, "Parent-child relationship disorders: what do the child vulnerability scale and the parent protection scale measure?" Clinical Pediatrics, vol. 38, no. 6, pp. 347-356, 1999.

[36] R. J. Simeonsson, M. Leonardi, D. Lollar, E. Bjorck-Akesson, J. Hollenweger, and A. Martinuzzi, "Applying the international classification of functioning, disability and health (ICF) to measure childhood disability," Disability and Rehabilitation, vol. 25, no. 11-12, pp. 602-610, 2003.

[37] N. Bayley, Manual for the Bayley Scales of Infant and Toddler Development, The Psychological Corporations, San Antonio, Tex, USA, 3rd edition, 2006.

[38] T. M. Achenbach and L. A. Rescorla, Manual for the Achenbach System of Empirically Based Assessment, University of Vermont, Research Center for Children, Youth, and Families, Burlington, Vt, USA, 2000.

[39] D. Wechsler, Manual for the Preschool and Primary Scale of Intelligence, The Psychological Corporation, San Antonio, Tex, USA, 3rd edition, 2002.

[40] K. E. Berry, N. A. Buktenica, and N. Berry, Beery-Buktenica Developmental Test of Visual-Motor Integration, NCS Pearson Inc., Minneoaplis, MN, USA, 5th edition, 2004.

[41] C. R. Reynolds and R. W. Kamphaus, Manual for the Behaviour Assessment System for Children, American Guidance Services, Inc., Circle Pines, Minn, USA, 2nd edition, 2004, (rating scale 2.5-5, 6-18 years).

[42] P. L. Harrison and T. Oakland, Manual for the Adaptive Behavior Assessment System, The Psychological Corporation, San Antonio, Tex, USA, 2nd edition, 2003, (0-5, 5-21 years).
[43] J. W. Varni, M. Seid, and P. S. Kurtin, "PedsQL"TM 4.0: reliability and validity of the pediatric quality of life inventory ${ }^{\mathrm{TM}}$ version 4.0 generic core scales in healthy and patient populations," Medical Care, vol. 39, no. 8, pp. 800-812, 2001.

[44] K. Uzark, K. Jones, T. M. Burwinkle, and J. W. Varni, "The Pediatric Quality of Life Inventory ${ }^{\mathrm{TM}}$ in children with heart disease," Progress in Pediatric Cardiology, vol. 18, no. 2, pp. 141-148, 2003.

[45] Clinical Evaluation of Language Fundamentals, Preschool, The Psychological Corporation, San Antonio, Tex, USA, 2nd edition, 2004.

[46] D. Wechsler, Manual of the Intelligence Scale for Children, The Psychological Corporation, San Diego, Tex, USA, 4th edition, 2004.

[47] D. Wechsler, Manual for the Wechsler Individual Achievement Test, The Psychological Corporation, San Diego, Tex, USA, 2nd edition, 2001.

[48] M. Korkman, U. Kirk, and S. Kemp, Clinical and Interpretative Manual for the NEPSY - II, The Psychological Corporation, San Antonio, Tex, USA, 2nd edition, 2007.

[49] G. A. Gioia, P. K. Isquith, S. C. Guy, and L. Kentworthy, Behaviour Rating Inventory of Executive Function-Parent Form, Psychological Assessment Resources Inc., Lutz, Fla, USA, 2001.

[50] G. M. Bedell, "Developing a follow-up survey focused on participation of children and youth with acquired brain injuries after discharge from inpatient rehabilitation," $\mathrm{Neu}$ roRehabilitation, vol. 19, no. 3, pp. 191-205, 2004.

[51] R. Goodman, T. Ford, H. Simmons, R. Gatward, and H. Meltzer, "Using the Strengths and Difficulties Questionnaire (SDQ) to screen for child psychiatric disorders in a community sample," British Journal of Psychiatry, vol. 177, pp. 534539, 2000.

[52] G. Casto and M. A. Mastropieri, "The efficacy of early intervention programs: a meta-analysis," Exceptional children, vol. 52, no. 5, pp. 417-424, 1986.

[53] S. R. Harris, "Efficacy of early intervention in pediatric rehabilitation: a decade of evaluation and review," Pediatric Rehabilitation, vol. 2, pp. 725-742, 1991.

[54] D. H. Freed, C. M. T. Robertson, R. S. Sauve et al., "Intermediate-term outcomes of the arterial switch operation for transposition of great arteries in neonates: alive but well?" Journal of Thoracic and Cardiovascular Surgery, vol. 132, no. 4, pp. 845-852, 2006.

[55] R. E. Neufeld, B. G. Clark, C. M. T. Robertson, D. M. Moddemann, I. A. Dinu, and A. R. Joffe, "Five-year neurocognitive and health outcomes after neonatal Arterial Switch operation," Journal of Thoracic and Cardiovascular Surgery, vol. 136, pp. 1413-1421, 2008.

[56] D. E. Creighton, C. M. T. Robertson, R. S. Sauve et al., "Emotional, behavioral and adaptive outcomes at 5 years of age for children with complex cardiac surgery at 6 weeks of age or younger," Paediatrics and Child Health, vol. 15, no. 71, 2010, abstract 192.

[57] J. C. Anderson, C. M. T. Robertson, A. R. Joffe et al., "Prevalence and profile of cerebral palsy four years after newborn complex heart surgery," American Academy for Cerebral Palsy and Developmental Medicine, vol. 51, no. 5, pp. 30-31, 2009, Abstract no. G 7 .

[58] J. Atallah, I. A. Dinu, A. R. Joffe et al., "Two-year survival and mental and psychomotor outcomes after the Norwood procedure: an analysis of the modified Blalock-Taussig shunt and right ventricle-to-pulmonary artery shunt surgical eras," Circulation, vol. 118, no. 14, pp. 1410-1418, 2008. 
[59] S. E. Henderson, D. A. Sugden, and A. L. Barnett, Movement Assessment Battery for Children, Harcourt Assessment, London, UK, 2nd edition, 2007.

[60] G. Y. Alton, C. M. T. Robertson, R. Sauve et al., "Early childhood health, growth, and neurodevelopmental outcomes after complete repair of total anomalous pulmonary venous connection at 6 weeks or younger," Journal of Thoracic and Cardiovascular Surgery, vol. 133, no. 4, pp. 905-911, 2007.

[61] A. R. Joffe, C. M. T. Robertson, A. Nettel-Aguirre, I. M. Rebeyka, and R. S. Sauve, "Mortality after neonatal cardiac surgery: prediction from mean arterial pressure after rewarming in the operating room," Journal of Thoracic and Cardiovascular Surgery, vol. 134, no. 2, pp. 311-318, 2007.

[62] J. Blackwood, A. R. Joffe, C. M. T. Robertson et al., "Association of hemoglobin and transfusion with outcome after operations for hypoplastic left heart," Annals of Thoracic Surgery, vol. 89, no. 5, pp. 1378-1384.e2, 2010.

[63] L. Lequier, A. R. Joffe, C. M. T. Robertson et al., "Twoyear survival, mental, and motor outcomes after cardiac extracorporeal life support at less than five years of age," Journal of Thoracic and Cardiovascular Surgery, vol. 136, no. 4, pp. 976-983, 2008.

[64] P.-Y. Cheung, N. Chui, R. A. Joffe, I. M. Rebeyka, and C. M. T. Robertson, "Post-operative lactate concentrations predict the outcome of infants age 6 weeks or less after intercardiac surgery: a cohort follow-up to 18 months," Journal of Thoracic and Cardiovascular Surgery, vol. 130, pp. 837-843, 2005.

[65] D. E. Creighton, C. M. T. Robertson, R. S. Sauve et al., "Neurocognitive, functional, and health outcomes at 5 years of age for children after complex cardiac surgery at 6 weeks of age or younger," Pediatrics, vol. 120, no. 3, pp. e478-e486, 2007.

[66] C. A. Joynt, C. M. T. Robertson, P.-Y. Cheung et al., "Two-year neurodevelopmental outcomes of infants undergoing neonatal cardiac surgery for interrupted aortic arch: a descriptive analysis," Journal of Thoracic and Cardiovascular Surgery, vol. 138, no. 4, pp. 924-932, 2009.

[67] A. R. Joffe, L. Quinonez, and C. M. T. Robertson, "Outcomesafter heart transplantation in children under six years of age," The Annals of Thoracic Surgery. In press.

[68] G. Hansen, A. R. Joffe, A. Nettel-Aguirre et al., "Two-year survival and neurodevelopmental outcomes after cardiopulmonary resuscitation in neonatal patients after complex cardiac surgery," Resuscitation, vol. 82, no. 3, pp. 313-318, 2011.

[69] G. G. Guerra, C. M. T. Robertson, G. Y. Alton et al., "Effect of sedatives and analgesia drugs on the neurodevelopmental outcome of neonates after cardiac surgery," Critical Care Medicine, vol. 37, no. 12, p. A11, 2010.

[70] D. Casarett, J. H. T. Karlawish, and J. Sugarman, “Determining when quality improvement initiatives should be considered research: proposed criteria and potential implications," Journal of the American Medical Association, vol. 283, no. 17, pp. 2275-2280, 2000. 


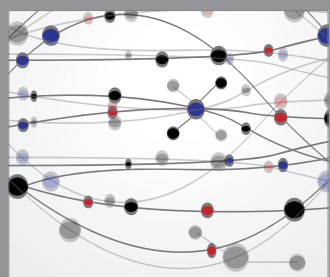

The Scientific World Journal
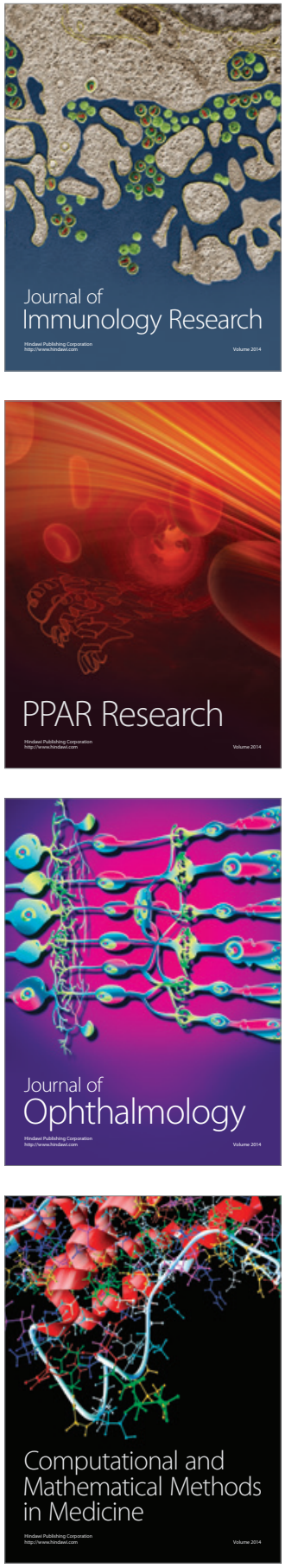

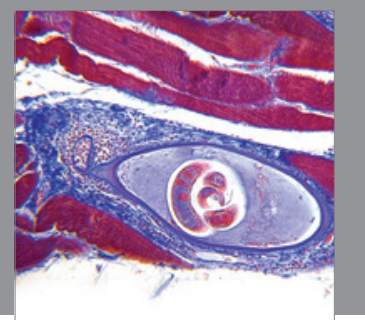

Gastroenterology

Research and Practice
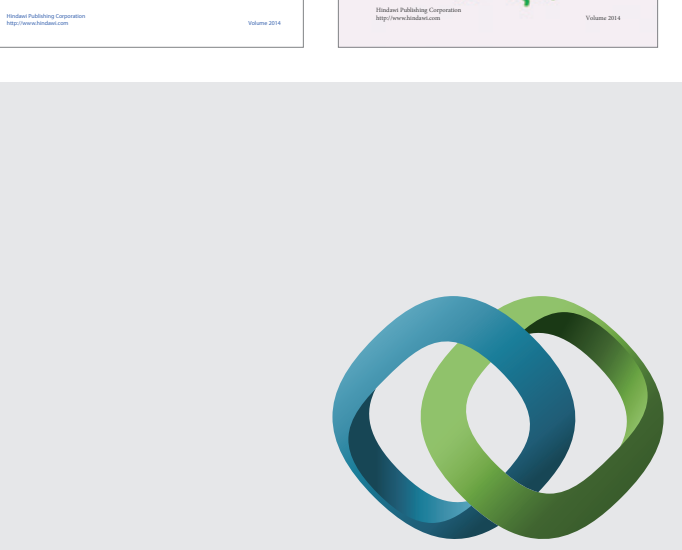

\section{Hindawi}

Submit your manuscripts at

http://www.hindawi.com
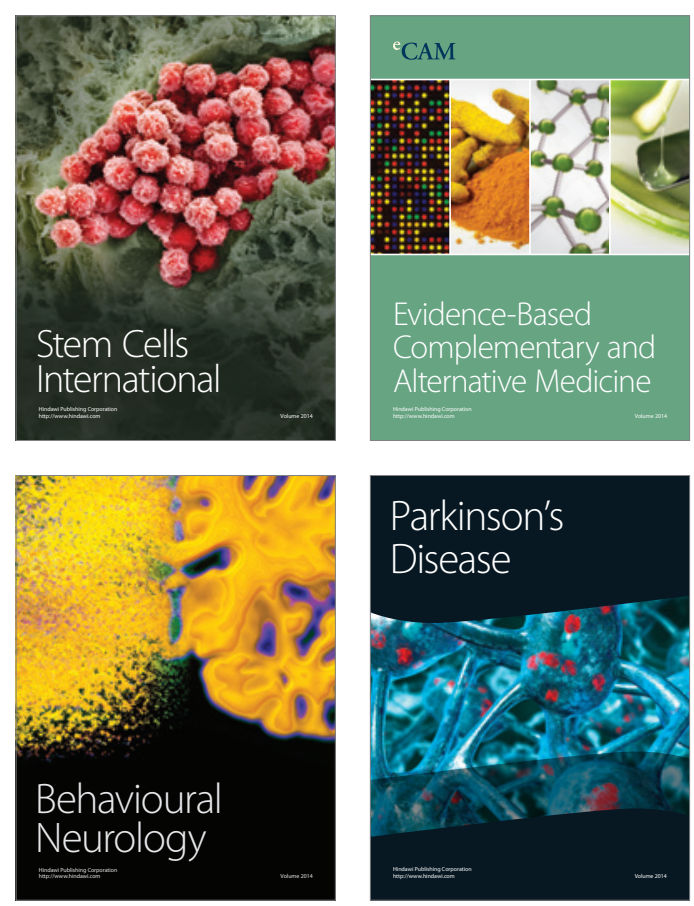

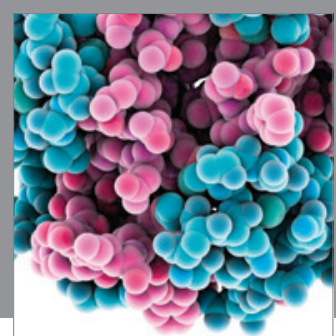

Journal of
Diabetes Research

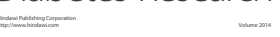

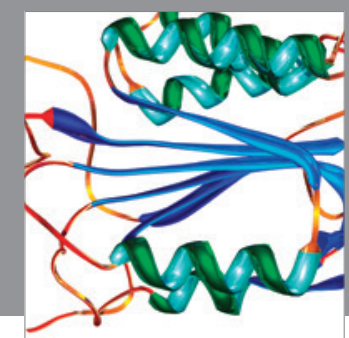

Disease Markers
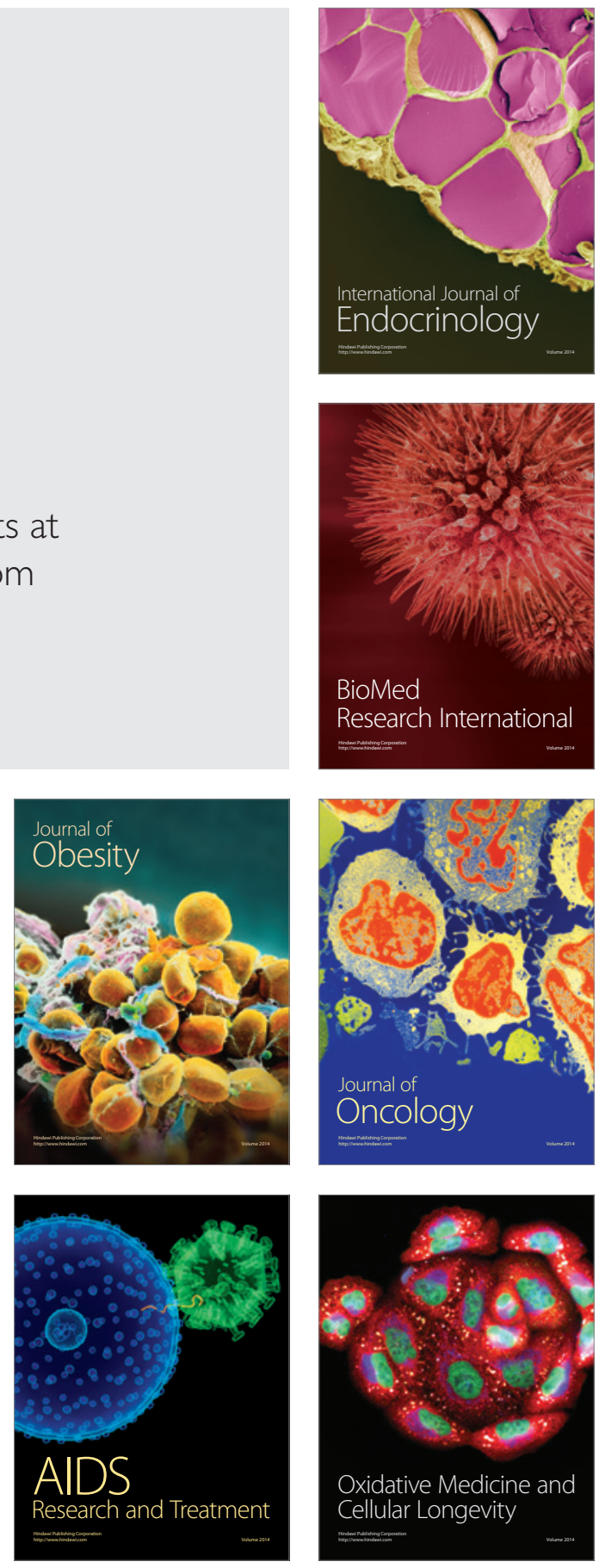